\title{
脳底動脈瘤への approach
}

\section{一optic-carotid triangle からの接近法一}

\author{
鄭光 珍, 長 沢史朗 \\ 米川 泰弘，半田肇
}

\section{Surgical Approach to Basilar Artery Aneurysms -Pterional approach via the optic-carotid triangle-}

Kwang Jin Chung, M. D., Shiro Nagasawa, M. D., Yasuhiro Yonekawa, M. D., and Hajime HANDA, M. D.

Department of Neurosurgery, Kyoto University Medical School, Kyoto, Japan

Summary: Two routes in the pterional approach to the distal basilar artery aneurysms have been known: one is via the space between the optic nerve and the internal carotid artery (opticcarotid triangle: OCT), and the other is lateral to the ICA (retrocarotid approach: RCA). Although the approach via the OCT has several advantages of its own, it had been considered applicable to very limited cases. We successfully clipped such aneurysms via OCT in four cases out of 12 cases (33\%), and the neuroradiological findings observed in these cases are analyzed and reported.

Measurements were made on the following items on the carotid angiogram of the cases operated via the OCT (OCT group) and the RCA (RCA group): the distance of ICA bifurcation from the midline (D) and the height of ICA bifurcation from the baseline between the anterior and posterior clinoid processes $(\mathrm{H})$. Although these two values seemed to be higher in the OCT than in the RCA group, no significant difference was found. The product of $D$ and $H(D \times H)$ was observed to be significantly higher in the OCT than in the RCA group. The value of $\mathrm{D} \times$ $\mathrm{H}$ is considered one of the indicate of the size of the OCT and has proved to be useful in judging whether the approach via the OCT is applicable or not.

Key words :

- aneurysm

The approach via the OCT has several advantages, such as no injury to the oculomotor nerve, less retraction to the ICA and easy visualization of the P1 segment of the opposite side. The space of the OCT can be used not only for clipping itself but also as a line of sight to the deep structures as well as clips applied from other routes.

- basilar artery

- neck clipping

- operation

- pterional approach 


\section{はじめに}

脳底動脈末梢部動脈瘤に対する外科的接近法の 1 つとし て pterional approach が広く採用されているが, 内頸動脈 の外側からの接近法 (retrocarotid approach, 以下 RCA と 略す)が一般的で, 視神経と内頸動脈との間 (optic-carotid triangle, 以下 OCT と略す) からの接近法の可能性は著し く低く数\%と言われている. 今回われわれは OCTより接 近し動脈瘤のクリッピングをしえた症例につき神経放射線 学的に検討したので報告する.

\section{対象および方法}

京大病院脳神経外科で扱った脳底動脈分岐部動脈瘤 (BH と略す) あるいは脳底動脈上小脳動脈分岐部動脈瘤 (BASCA と略す) を有した22症例中, pterional approach にて手術した12症例が本研究の対象である.この12症例中 OCT から接近してクリッピングしえたのは 4 症例であり, 他の 8 症例では OCT からは接近できず RCA にて手術し た (Table 1).

OCT からの接近が可能か否かを術前に知る目的で，脳 血管撮影写真にて種々の計測を行った (Fig. 1). 計測部位 は頸動脈撮影正面像で内頸動脈分岐部の正中線からの距離 (D), 頸動脈および椎骨動脈撮影側面像において前床突 起 と後床突起とを結ぶ基準線から内頸動脈分岐部までの高さ (H)などである.

\section{結果}

OCT より接近しえた 4 症例 (OCT 群) と, 接近しえず に RCA にて手術した 8 症例（RCA 群）とにわけて計測 結果を検討した。内頸動脈分岐部の正中線からの距離(D)

Table 1 Summary of cases

\begin{tabular}{llllll}
\hline & $\begin{array}{c}\text { Age \& } \\
\text { sex }\end{array}$ & $\begin{array}{c}\text { Location of } \\
\text { aneurysm }\end{array}$ & SAH & Result & $\begin{array}{c}\text { Oculomotor } \\
\text { palsy }\end{array}$ \\
\hline OCT & $70 \mathrm{~F}$ & BH & + & good & \\
& $62 \mathrm{~F}$ & BH \& BASCA & + & fair & \\
& $63 \mathrm{~F}$ & BH & + & good & \\
& $59 \mathrm{~F}$ & $\mathrm{BH}$ & + & good & \\
$\mathrm{RCA}$ & $50 \mathrm{M}$ & $\mathrm{BH}$ & + & good & + \\
& $45 \mathrm{~F}$ & BH & + & poor & \\
& $44 \mathrm{~F}$ & BH & + & fair & + \\
& $61 \mathrm{~F}$ & BASCA & & dead & \\
& $49 \mathrm{M}$ & BASCA & + & poor & \\
& $48 \mathrm{~F}$ & BH & + & good & \\
& $69 \mathrm{~F}$ & BASCA & + & good & + \\
$32 \mathrm{~F}$ & BASCA & + & good & \\
\hline
\end{tabular}

は OCT 群では16.4 $1.9 \mathrm{~mm}$ と RCA 群と比較して大きい 傾向を認めたものの有意ではなかった(Fig. 2). 内頸動脈 分岐部の基準線からの高さ $(\mathrm{H})$ に拈いても OCT 群では $8.9 \pm 0.9 \mathrm{~mm}$ であり同様の結果であった (Fig. 3). そこで 両計測値の積 $(\mathrm{D} \times \mathrm{H})$ を計算したところ OCT 群では 144.8 土16.3 であり, RCT 群の $93.8 \pm 17.9$ と比べて有意に大きな 数值を取ることがわかった（Fig. 5). 脳底動脈分岐部の基 準線からの高さや後床突起からの距離あるいは内頸動脈分 岐部からの距離などの計測值においては両群の間に差を認 めなかった。

\section{検討}

OCT は内側の視神経, 外側の内頸動脈を二辺とする三 角形であり前大脳動脈 $\mathrm{A}_{1}$ 部が他の一辺を形成する(Fig. 5).

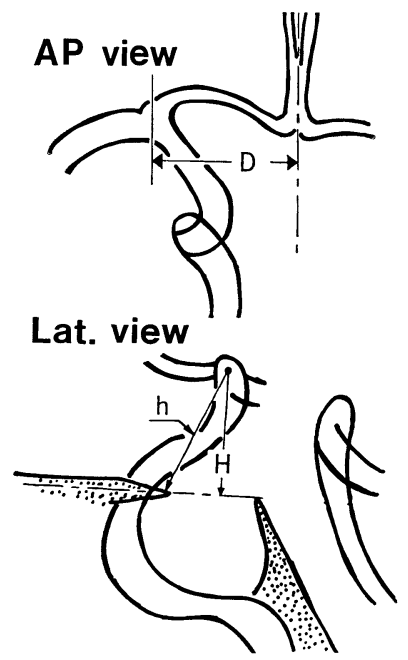

Fig. 1 Distance of internal carotid artery bifurcation (ICBIF) from midline in AP view : D, and height of IC-BIF from baseline between anterior and posterior clinoid processes in lateral view: $\mathrm{H}$.

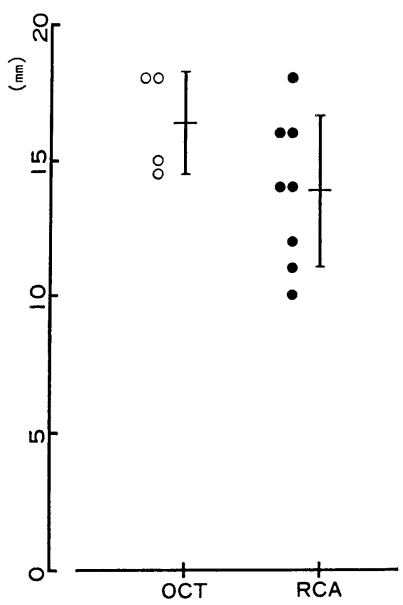

Fig. 2 Distance of IC-BIF from midline : D 
pterional approach による脳底動脈末梢部動脈瘤 クリッ ピングを提唱した Yasargil ${ }^{4)}$ は，視神経と内頸動脈との 間に $5 \sim 10 \mathrm{~mm}$ の幅がある場合にはこの間隙より処置可能

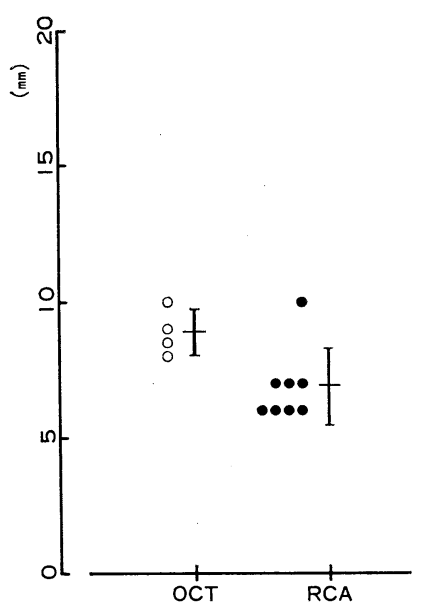

Fig. 3 Height of IC-BIF from baseline: $\mathrm{H}$

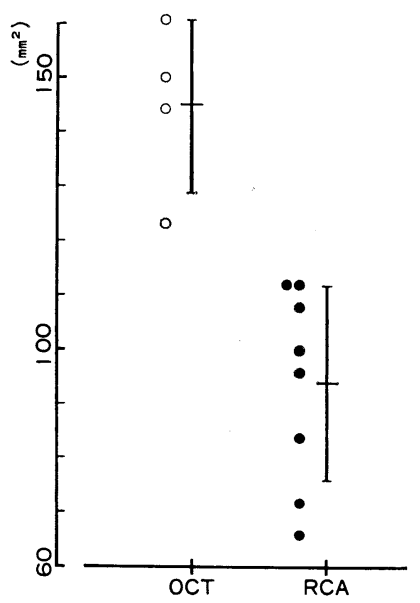

Fig. $4 \quad D \times H$

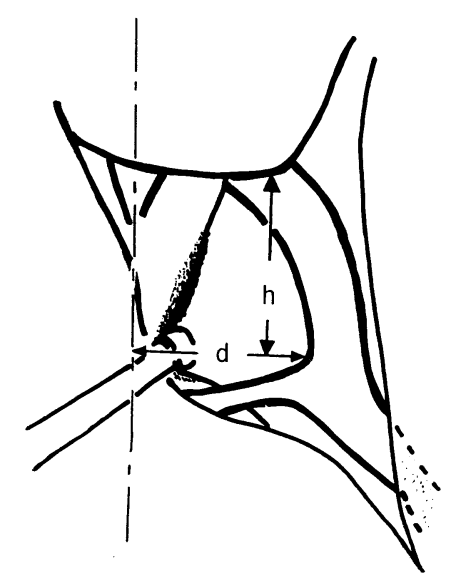

Fig. 5 Schema of the operative field.
としている。しかしながらこの間隙は一般的にかなり狭 くまた穿通枝が多いとされているため，この部位よりの接 近は著しく困難と考えられていた. OCTからの接近が可能 であった頻度を文献的に検討してみても，1/3 の症例に接 近可能であったとする Samson ${ }^{1)}$ の報告は例外的であり， 数\%以下という報告が多( ${ }^{2) 3}$ ）。本研究では33\% (4/12例) といら高い頻度で OCT からの接近が可能であったが，そ の理由として開頭術の際にはまずこの接近法を試みるとい った姿勢によるところが大きいと考えられる。いずれにし ても OCT からの接近法は従来考兄られている頻度以上に 採用可能と推定される.

山浦 ${ }^{3)}$ は脳底動脈末梢部動脈瘤に対する pterional approach に関する神経放射線学的計測を行い，基準線より 内頸動脈分岐部までの高さが $10 \mathrm{~mm}$ 以上で脳底動脈分岐 部までの高さが $5 \sim 10 \mathrm{~mm}$ の場合には手術は比較的容易で あり，また一般的には OCT からの接近はあまり期待でき ないが前大脳動脈 $A_{1}$ 部が長い場合のみ可能性があるとし ている，術中に脳ベラあるいは吸引管で視神経を圧迫した ときの模式㘠 (Fig. 5) に示したようにOCT の底辺をd， 高さをhとすると, 本接近法の入口部すなわち OCT の大 きさ $\mathrm{S}$ は $\mathrm{S}=\mathrm{d} \times \mathrm{h} / 2$ で表わされる.ここで脳血管撮影写 真の計測值と d, h との関係を検討すると, $\mathrm{D}=\mathrm{d}, \mathrm{H} \fallingdotseq \mathrm{h}$ であるので $\mathrm{D} \times \mathrm{H}$ の大きさは $\mathrm{s}$ の大きさを表わす指標之考 えることができる。例数は少ないものの本研究では OCT 群の $\mathrm{D} \times \mathrm{H}$ の值は144.8 $8 \mathrm{RCT}$ 群の 93.8 と比較して有意 に大きな值をとっており，D×H の大きさは OCT からの 接近法の可能性を判断する指標となることがわかった.

OCT からの接近法の利点としては動眼神経麻痺をきた しがたいこと（Table 1), 内頸動脈への圧迫が少ないこと， 反対側後大脳動脈 $\mathrm{P}_{1}$ 部を確認しやすいことなどがあげられ る. OCT からクリッピングできない場合でも術野の解剖 学的関係の確認や, クリップ先端の確認など, この間隚の 利用価值は大きいと考えられる。

\section{文献}

1) Samson DS, Hodosh RM, Clark WK : Microsurgical evaluation of the pterional approach to aneurysms of the distal basilar circulation. Neurosurgery $3: 135-141$, 1975

2) Sugita K, Kobayashi S, Shintani A, et al: Microneurosurgery for aneurysms of the basilar artery. J Neurosurg $51: 615-620,1979$

3）山浦 晶：椎骨脳底動脈瘤の手術. Neurosurgeons $4: 375$ 383,1984

4) Yasargil MG, Antic J, Laciga R, et al: Microsurgical pterional approach to aneurysms of the basilar bifuration. Surg Neurol 6 : 83-91, 1976 